\title{
A new anesthetic protocol to medullary nerve roots access in rats
}

\author{
Deivid Ramos dos Santos ${ }^{1 *}$ (D), Renan Kleber Costa Teixeira² ${ }^{\mathbb{C}}$, Nayara Pontes de Araújo ${ }^{3}$ (D), Faustino \\ Chaves Calvo ${ }^{\mathbb{B}}$, Tiago Braga Duarte ${ }^{5}$ (D), Letícia Amanda Pinheiro de Ataíde $^{6}{ }^{\mathbb{D}}$, Rosa Helena de \\ Figueiredo Chaves $^{7}$, , Rui Sergio Monteiro de Barros ${ }^{8}$
}

1. Fellow Master degree. Postgraduate Program in Surgery and Experimental Research - Universidade do Estado do Pará (UEPA) - Belem (PA), Brazil.

2. MD. Department of Experimental Surgery - School of Medicine, Universidade do Estado do Pará (UEPA) - Belem (PA), Brazil.

3. Graduate student. School of Medicine - Universidade Federal do Pará (UFPA) - Belem (PA), Brazil. Conception, interpretation of data, manuscript writing.

4. Graduate student. School of Medicine - Universidade Federal do Pará (UFPA), Belem (PA), Brazil.

5. Graduate student. School of Medicine - Universidade Federal do Pará (UFPA) - Belem (PA), Brazil.

6. Graduate student. School of Medicine - Universidade do Estado do Pará (UEPA) - Belem (PA), Brazil.

7. Fellow PhD degree. Postgraduate Program in Health and Animal Production in Amazon - Universidade Federal Rural da Amazônia (UFRA) - Belem (PA), Brazil.

8. PhD, Associate Professor. Department of Experimental Surgery - School of Medicine - Universidade do Estado do Pará (UEPA) - Belem (PA), Brazil.

\begin{abstract}
Purpose: To describe a new anesthetic protocol medullary and nerve roots access and in Rattus norvegicus. Methods: Seventy female Wistar rats $(n=70)$ were used. The animals were randomly divided into two laminectomy groups: cervical $(n=40)$ and thoracic $(n=30)$. In cervical group, a right posterior hemilaminectomy was performed to access the nerve roots. In thoracic group, a laminectomy of the eighth thoracic vertebra was accomplished. Thirty-five rats (20 cervical and 15 thoracic) were submitted to old anesthetic protocol (ketamine $70 \mathrm{mg} / \mathrm{kg}$ plus xylazine $10 \mathrm{mg} / \mathrm{kg}$ ); and the 35 other animals ( 20 cervical and 15 thoracic) were submitted to a new anesthetic protocol (ketamine $60 \mathrm{mg} / \mathrm{kg}$, xylazine $8 \mathrm{mg} / \mathrm{kg}$ and fentanyl $0.03 \mathrm{mg} / \mathrm{kg}$ ). Results: The time to complete induction was $4.15 \pm 1.20 \mathrm{~min}$ in ketamine, xylazine and fentanyl group, and it was $4.09 \pm 1.47 \mathrm{~min}$ in the ketamine and xylazine group. There was no correlation in the time required to perform the cervical laminectomy in the old anesthetic protocol. In all groups, the animals submitted to the old anesthetic protocol had a higher level of pain on the first and third postoperative days than the animals submitted to the new anesthetic protocol. Conclusion: The new anesthetic protocol reduces the surgical time, allows better maintenance of the anesthetic plan, and brings more satisfactory postoperative recovery.
\end{abstract}

Key words: Microsurgery. Anesthesia. Animal Experimentation. Rats.

*Corresponding author: deivid_ramos45@hotmail.com | (55 91)98234-1393

Received: May 09, 2021 | Review: July 11, 2021 | Accepted: Aug 12, 2021

Conflict of interest: Nothing to declare.

Research performed at Laboratory of Experimental Surgery, Universidade do Estado do Pará (UEPA), Belem-PA, Brazil. 


\section{Introduction}

Spinal nerve avulsion injuries are devastating both from the functional and the psychosocial points of view, due to poor neural regeneration, especially the preganglionic lesions, that, as a rule, have the worst prognosis owing to their considerable failure rate ${ }^{1-3}$. They occur when the nerves that connect the spinal cord to the muscles are arranged (avulsed). As root avulsion is a longitudinal injury to the spinal cord, it differs from other peripheral nerve injuries and is beyond surgical repair ${ }^{3,4}$.

Avulsion injuries has grown as the number of motorcycle accidents increases ${ }^{1,2}$. Unfortunately, in $70 \%$ of these accidents, at least one root is completely avulsed, due to the high impact related to the biomechanics of trauma ${ }^{2,3}$.

Actually, the surgical strategy after root avulsion injury is palliative and culminates in deficient functional recovery. In the last 20 years, in only some experimental models, it has been reported that avulsioned root nerve neurotization is possible by reimplantation of the injured root in the spinal cord ${ }^{5,6}$.

Years later, the first clinical cases submitted to replantation surgery for single roots in humans were described, and limited functional recovery of the shoulder and elbow was report ${ }^{7}$. The use of experimental avulsion models is one of the key steps to obtain good functional results in this repair ${ }^{7-10}$.

Although laminectomy is a widely performed technique, surgical description and an anesthetic protocol that brings better postoperative recovery are, in most cases, neglected and rarely reported.

Therefore, this research can contribute to the improvement of experimental surgical techniques for implantation of avulsed roots and their subsequent studies to assess neural regeneration. In this work, a new anesthetic protocol medullary and nerve roots access and in Rattus norvegicus was described.

\section{Methods}

This research followed the rules of the Brazilian Law for Animal Care (Law no. 11.794/08) and Animal Research: Reporting of In Vivo Experiments (ARRIVE) guideline. It was approved by the Animal Use and Care Committee at Universidade do Estado do Pará (28/18).

Seventy female Wistar rats $(n=70)$ obtained from the Animal Colony of Instituto Evandro Chagas were used. The sample size was decided intentionally by the researchers. The animals were kept in a vivarium of the Experimental Surgery Laboratory at Universidade do Estado do Pará (Brazil) with a controlled environment. Water and food were provided ad libitum.
The animals were randomly divided into two groups: cervical $(n=40)$ and thoracic $(n=30)$. In cervical group $(\mathrm{CLG})$, a right posterior laminectomy surgery was performed, to access the nerve roots and simulate a brachial plexus avulsion model of to $\mathrm{C7}$ injury. In thoracic group (TLG), the animals were submitted to a partial spinal cord injury.

The procedures were performed under video system ${ }^{11,12}$, composed by a high-definition Sony ${ }^{\odot}$ camcorder DCR-SR42 set to $52 \times$ magnification connected with a $4 \mathrm{~K} 55$-inch curved television by a digital HDMI cable. Two-low intensity halogen light source were used near to the camera to provide adequate illumination of the operative field.

Thirty-five rats (20 cervical and 15 thoracic) were submitted to old anesthetic protocol (OAP) ${ }^{13-15}$, with ketamine (K) $70 \mathrm{mg} / \mathrm{kg}$ plus xylazine (X) $10 \mathrm{mg} / \mathrm{kg}$, intraperitoneal, proving to be effective during the operative period without intercurrences, as used in the experimental surgery laboratory ${ }^{16,17}$. The other 35 animals ( 20 cervical and 15 thoracic) were submitted to a new anesthetic protocol (NAP), with ketamine $60 \mathrm{mg} / \mathrm{kg}$, xylazine $8 \mathrm{mg} / \mathrm{kg}$ and fentanyl $0.03 \mathrm{mg} / \mathrm{kg}$, intraperitoneal ${ }^{16}$. Fentanyl was repeated for every 30 minutes until the end of the surgery.

To confirm the anesthesia, the withdraw reflex of the forelimb and hind limb and the reflexes of the eyelid and tail were observed using forceps. Surgical anesthetic depth was defined when the animals lost at least three out of the four reflexes ${ }^{18}$.

Confirmed the anesthesia, depending on the group, the cervical or thoracic region was shaved. Antisepsis was performed with povidone-iodine. The animals were placed in a horizontal ventral position above a plastic support on cervical or thoracic region to flex the spine to increase the interlaminar space.

A 4-cm incision was performed in the cervical or thoracic region above the column. The subcutaneous tissue was carefully laid back, and there was the blunt dissection of the paraspinal muscles to expose the cervical or thoracic spine. Meticulous hemostasis using bipolar cauterization were performed. Two-mL of lidocaine $2 \%$ was dripped in this area for better anesthetic management. The paraspinal muscles were pushed laterally with retractors. The spinous process of T2 was used as an anatomical landmark to identify the other vertebras.

In both groups, the procedure ended with the suture of muscles with 5-0 nylon and skin using 4-0 nylon. The animals were followed up by 14 days postoperatively. In all groups, the animals received tramadol hydrochloride ${ }^{13} 4 \mathrm{mg} / \mathrm{kg}$ at $12 / 12 \mathrm{~h}$ for up to five days by subcutaneous, and lidocaine topical was used in the incision at $12 / 12 \mathrm{~h}$ also for up to five days. In all groups, enrofloxacin was administrated by subcutaneous at $10 \mathrm{mg} / \mathrm{kg}$ once a day until seven days, to prevent meningeal infection. It was not necessary to perform the bladder massage. The animals were housed 
in isolated cages after the procedure to avoid injuries and pressure ulcers.

The parameters analyzed were time to surgical access and Rat Grimace Scale ${ }^{14}$. The scale was performed at the first, third, seventh and fourth quarter postoperatively day. The software BioEstat ${ }^{\odot} 5.4$ was used. All data were expressed as means \pm standard deviation. The Student's $t$-test was used to compare tests score by groups, and the Fisher's exact test was applied to compare tests score by weight. Statistical significance was assumed at $p<0.05$.

\section{Results}

All animals survived during the study period.

In all groups, the time to complete induction was $4.15 \pm 1.20 \mathrm{~min}$ in the NAP group (ketamine, xylazine and fentanyl), and it was $4.09 \pm 1.47 \mathrm{~min}$ in the OAP group (ketamine and xylazine). There was not statistically difference $(p=0.73)$.

In CLG and TLG groups, the old protocol showed more signs of pain during the surgery $(18 / 20$ and $12 / 15$, respectively) than the new protocol $(3 / 20$ and $3 / 15$, respectively) $(p<0.0001)$. The necessity of new anesthetic dose during the surgery was 10/40 in CLG (new anesthetic protocol: $3 / 20 v s$. old protocol: $7 / 20 ; p<0.0001)$ and it was 8/30 in TLG (new anesthetic protocol: $2 / 20 \mathrm{vs}$. old protocol: $6 / 20 ; p<0.0001$ ).

In CLG, the time required to complete each procedure was $41.35 \pm 5.67 \mathrm{~min}$. When comparing it considering the anesthetic protocol, the time required was $38.16 \pm 5.95 \mathrm{~min}$ in the new protocol and it was $59.92 \pm 11.36 \mathrm{~min}$ in the old protocol. The difference between the groups was statistically significant $(p=0.03)$.

In TLG, the time required to complete each procedure was $41.35 \pm 5.67 \mathrm{~min}$. When comparing it for anesthetic protocol, the time required was $38.16 \pm 5.95 \mathrm{~min}$ in the new protocol and it was $59.92 \pm 11.36 \mathrm{~min}$ in the old protocol. The difference between the groups was statistically significant $(p=0.02)$.

The correlation analysis between time and the order of surgeries showed reduction in the time required to perform the surgery (Pearson's correlation coefficient $=$ $-0.72,95 \%$ confidence interval $-95 \% \mathrm{IC}=-0.39--0.85$, $\mathrm{p}<0.01$ ) in the new anesthetic protocol. There was no correlation in the time required to perform the cervical laminectomy in the old anesthetic protocol.

When comparing the groups according to the Rat Grimace Scale ${ }^{18}$, the animals submitted to the old anesthetic protocol had a higher level of pain on the first and third postoperative days than the animals submitted to the new anesthetic protocol $(p<0.0001)$. There were no significant differences between the groups on the 14th postoperative day $(p>0.05)$ (Table 1$)$.
Table 1 - Mean scores of Rat Grimace Scale according to the groups submitted to anesthetic protocol.

\begin{tabular}{|c|c|c|c|c|}
\hline \multirow[b]{2}{*}{ Parameter } & \multicolumn{4}{|c|}{ Postoperatively day } \\
\hline & First & Third & Seventh & $\begin{array}{l}\text { Fourth } \\
\text { quarter }\end{array}$ \\
\hline \multicolumn{5}{|c|}{ ketamine $70 \mathrm{mg} / \mathrm{kg}$ plus xylazine $10 \mathrm{mg} / \mathrm{kg}$} \\
\hline Thoracic group & $0.78 \pm 0.3$ & $0.54 \pm 0.2$ & $0.26 \pm 0.14$ & $0.16 \pm 0.12$ \\
\hline Cervical group & $0.65 \pm 0.3$ & $0.49 \pm 0.2$ & $0.23 \pm 0.12$ & $0.19 \pm 0.13$ \\
\hline \multicolumn{5}{|c|}{$\begin{array}{c}\text { ketamine } 60 \mathrm{mg} / \mathrm{kg}, \text { xylazine } 8 \mathrm{mg} / \mathrm{kg} \\
\text { and fentanyl } 0.03 \mathrm{mg} / \mathrm{kg}\end{array}$} \\
\hline Thoracic group & $0.40 \pm 0.2$ & $0.24 \pm 0.1$ & $0.18 \pm 0.13$ & $0.14 \pm 0.10$ \\
\hline Cervical group & $0.35 \pm 0.2$ & $0.21 \pm 0.1$ & $0.17 \pm 0.12$ & $0.13 \pm 0.11$ \\
\hline
\end{tabular}

\section{Discussion}

Experimental models of spinal cord access are clearly invasive and trigger perioperative pain. However, the transoperatory anesthetic protocol and appropriate postoperative analgesics are not performed or registered with rigor, although their correct application reduces the variation in results due to pain-induced stress ${ }^{18-21}$.

It is known that the adequate anesthetic protocol directly influences the surgical success and the recovery of the experimental model ${ }^{8}$. When incorrect, it can bring perioperative risks and strongly alter the results studied ${ }^{19}$, mainly in spine surgery, because of its considerable failure rate, neurological deficits in the postoperative period and pain ${ }^{13}$.

Although laboratory rats are one of the most used models in several research areas, there is still no unanimous anesthetic protocol for certain complex microsurgical procedures, such as posterior intradural access to the spinal $\operatorname{cord}^{13,20-23}$.

Ketamin is classified as a dissociative anesthetic agent and does not provide deep anesthesia when used by itself. For this reason, ketamin needs a combination of sedatives such as xylazine. The dose most used in rats is $80-100 \mathrm{mg} / \mathrm{kg}$ for ketamin and $10 \mathrm{mg} / \mathrm{kg}$ for xylazine. Fentanyl is a $\mu$-opioid receptor agonist and, despite it was used to modulate intraoperative pain, its effect on pain modulation in spinal cord models has not yet been elucidated ${ }^{24,25}$.

In relation to the induction time, there was no statistical difference until complete induction between groups $(P=0.73)$. Although numerically the rats submitted to the new anesthetic protocol took a little longer, the animals received a lower dose of anesthetic, increasing operative safety.

The animals submitted to the new anesthetic protocol had less signs of pain during the operative procedure. On the 
other hand, those ones submitted to the combination of ketamine and xylazine needed new doses of anesthetics, increasing the risk of adverse events, such as hypothermia, bradycardia and respiratory depression ${ }^{24,25}$. In this sense, the new anesthetic protocol proves to be safer and allows a surgical procedure with reduced potential risks.

There was a decrease in operative time in all animals submitted to the new anesthetic protocol. This is mainly due to safer anesthesia, with an induction plan and lasting maintenance for the chosen surgical procedure.

The general operative time was longer in animals submitted to the old protocol. This is justified by the early superficialization of the animal, the need of new anesthetic administration, checking the absence of reflexes and, finally, restarting the surgery.

According to scores of Rat Grimace Scale, better postoperative recovery was found in animals submitted to the new anesthetic protocol, mainly in first and third days after surgery, similar to that reported in other studies ${ }^{13,25}$. The pain scale has high sensitivity in the immediate postoperative period and, although its decrease does not necessarily mean spontaneous pain resolution, its application serves to refine our understanding of the best surgical recovery of the experiments ${ }^{24,27}$.

\section{Conclusions}

The new anesthetic protocol reduces the surgical time, allows better maintenance of the anesthetic plan, and brings more satisfactory postoperative recovery. Medullary nerve roots access needs to be performed by experienced researchers to avoid misinterpretation. Further studies are suggested using different anesthetic concentrations for a better understanding of the new protocol.

\section{Author's contribution}

Intellectual and scientific content of the study: Santos DR and Barros RSM; Conception and design the study: Santos DR; Acquisition and interpretation of data: Calvo FC, Duarte TB and Ataíde LAP; Interpretation of data: Santos DR, Teixeira RKB and Araújo NP; Manuscript preparation: Araújo NP and Duarte TB; Manuscript writing: Santos DR and Teixeira RKB; Critical revision: Chaves RHF; Final approval of the version to be published: Chaves RHF and Barros RSM.

\section{Data availability statement}

Data will be available upon request.

\section{Funding}

Not applicable.

\section{Acknowledgments}

Not applicable.

\section{References}

1. Carlstedt T. Nerve root replantation. Neurosurg Clin N Am. 2009;20(1):39-vi. https://doi.org/10.1016/j. nec.2008.07.020

2. Zheng $M X$, Hua $X Y$, Jiang $S$, Qiu $Y Q$, Shen $Y D, X u$ WD. Contralateral peripheral neurotization for a hemiplegic hindlimb after central neurological injury. J Neurosurg. 2018;128(1):304-11. https://doi. org/10.3171/2016.4.JNS152046

3. Wu CY, Jou IM, Yang WS, Yang CC, Chao LY, Huang $\mathrm{YH}$. Significance of the mass-compression effect of postlaminectomy/laminotomy fibrosis on histological changes on the dura mater and nerve root of the cauda equina: an experimental study in rats. J Orthop Sci. 2014;19(5):798-808. https://doi.org/10.1007/s00776014-0590-7

4. Noguchi T, Ohta S, Kakinoki R, Kaizawa Y, Matsuda S. A new cervical nerve root avulsion model using a posterior extravertebral approach in rats. J Brachial Plex Peripher Nerve Inj. 2013;8(1):8. https://doi.org/10.1186/1749-7221-8-8

5. Carlstedt TP, Hallin RG, Hedstrom KG, Nilsson-Remahl IA. Functional recovery in primates with brachial plexus injury after spinal cord implantation of avulsed ventral roots. J Neurol Neurosurg Psychiatry. 1993;56:649-54. https://doi. org/10.1136/jnnp.56.6.64

6. Cullheim S, Carlstedt $T$, Linda $H$, Risling $M$, Ulfhake B. Motoneurons reinnervate skeletal muscle after ventral root implantation into the spinal cord of the cat. Neuroscience. 1989;29:725-33. https://doi. org/10.1016/0306-4522(89)90144-9

7. Bergerot A, Shortland PJ, Anand P, Hunt SP, Carlstedt T. Co-treatment with riluzole and GDNF is necessary for functional recovery after ventral root avulsion injury. Exp Neurol. 2004;187:359-66. https://doi.org/10.1016/j. expneurol.2004.02.003

8. Zhou LH, Wu W. Survival of injured spinal motoneurons in adult rat upon treatment with glial cell line-derived neurotrophic factor at 2 weeks but not at 4 weeks after root avulsion. J Neurotrauma. 2006;23:920-7. https://doi. org/10.1089/neu.2006.23.920

9. Gu HY, Chai H, Zhang JY, Yao ZB, Zhou LH, Wong WM, Bruce IC, Wu WT. Survival, regeneration and functional recovery of motoneurons after delayed reimplantation of avulsed spinal root in adult rat. Exp Neurol. 2005;192:89-99. https://doi.org/10.1016/j.expneurol.2004.10.019

10. Teixeira, RKC, Leal RA, Sabbá MF, Yamaki VN, Lemos MVV, Barros RS M. Evaluation of 2 low-cost high-definition video systemsforvenousanastomosis.SurgInnov.2020;27(4):3737. https://doi.org/10.1177/1553350620928185 
11. Harikrishnan VS, Krishnan LK, Abelson KSP. A novel technique to develop thoracic spinal laminectomy and a methodology to assess the functionality and welfare of the contusion spinal cord injury (SCI) rat model. PLoS One. 2019;14(7):e0219001. https://doi.org/10.1371/journal.pone.0219001

12. Barros RSM, Brito M, Moura G. Is it possible to do a microvascular anastomosis with an ordinary video camera? Experimental study. J Reconstr Microsurg. 2011;27(8):5038. https://doi.org/10.1055/s-0031-1284237

13. Chaves RHF, Souza CC, Furlaneto IP, Teixeira RKC, Oliveira $C P$, Rodrigues EM, Santos DASD, Silva RC, Penha NEAD, Lima AR. Influence of tramadol on functional recovery of acute spinal cord injury in rats. Acta Cir Bras. 2018;33(12):108794. https://doi.org/10.1590/s0102-865020180120000006

14. Sotocinal SG, Sorge RE, Zaloum A, Tuttle AH, Martin LJ, Wieskopf JS, Mapplebeck JC, Wei P, Zhan S, Zhang S, McDougall JJ, King OD, Mogil JS. The Rat Grimace Scale: a partially automated method for quantifying pain in the laboratory rat via facial expressions. Mol Pain. 2011;7:55. https://doi.org/10.1186/1744-8069-7-55.

15. Lee EJ, Silva SM, Simões Mde J, Montero EF. Effect of $\mathrm{N}$-acetylcysteine in liver ischemia-reperfusion injury after 30\% hepatectomy in mice. Acta Cir Bras. 2012;27(4):346-9. https://doi.org/10.1590/s0102-86502012000400011.

16. Somensi DN, Teixeira RKC, Feijó DH, Loureiro KD, Valente AL, Carvalho LTF, Calvo FC, Santos DRD, Barros RSM. Does the type of electrode affect the electromyoneurographic parameters in rats?1. Acta Cir Bras. 2019;34(3):e201900304. https://doi.org/10.1590/s0102-865020190030000004.

17. Teixeira RKC, Costa FLDS, Calvo FC, Santos DRD, Yasojima EY, Brito $\mathrm{MVH}$. Effect of copaiba oil in intestinal mucosa of rats submitted to hypovolemic shock. Arq Bras Cir Dig. 2019;32(3):e1451. https://doi.org/10.1590/0102-672020190001e1451.

18. Tsukamoto A, Niino N, Sakamoto M, Ohtani R, Inomata T. The validity of anesthetic protocols for the surgical procedure of castration in rats. Exp Anim. 2018;67(3):32936. https://doi.org/10.1538/expanim.18-0003.

19. De Rantere D, Schuster CJ, Reimer JN, Pang DS. The relationship between the Rat Grimace Scale and mechanical hypersensitivity testing in three experimental pain models. Eur J Pain. 2016;20(3):417-26. https://doi. org/10.1002/ejp.742. Epub 2015 Jul 1. PMID: 26132473.
20. Cicero L, Fazzotta S, Palumbo VD, Cassata G, Lo Monte Al. Anesthesia protocols in laboratory animals used for scientific purposes. Acta Biomed. 2018;89(3):337-42. https://doi.org/10.23750/abm.v89i3.5824

21. Hestehave S, Munro G, Christensen R, Brønnum Pedersen T, Arvastson L, Hougaard P, Abelson KSP. Is there a reasonable excuse for not providing post-operative analgesia when using animal models of peripheral neuropathic pain for research purposes? PLoS One. 2017;12(11):e0188113. https://doi.org/10.1371/journal.pone.0188113.

22. Philips $B H$, Weisshaar $C L$, Winkelstein $B A$. Use of the rat grimace scale to evaluate neuropathic pain in a model of cervical radiculopathy. Comp Med. 2017;67(1):34-42.

23. Yamagami T, Matsui $H$, Tsuji H, Ichimura K, Sano A. Effects of laminectomy and retained extradural foreign body on cauda equina adhesion. Spine (Phila Pa 1976). 1993;18(13):1774-81. https://doi.org/10.1097/00007632199310000-00010

24. Stokes EL, Flecknell PA, Richardson CA. Reported analgesic and anaesthetic administration to rodents undergoing experimental surgical procedures. Lab Anim. 2009;43(2):149-54.

25. Gargiulo S, Greco A, Gramanzini M, Esposito S, Affuso A, Brunetti A, Vesce G. Mice anesthesia, analgesia, and care, Part I: anesthetic cons iderations in preclinical research. ILAR J. 2012;53(1):E55-69. https://doi.org/10.1093/ ilar.53.1.55. PMID: 23382271

26. Jiron JM, Mendieta Calle JL, Castillo EJ, Abraham AM, Messer JG, Malphurs WL, Malinowski C, Grove K, Reznikov LR, Zubcevic J, Aguirre Jl. Comparison of isoflurane, ketamine dexmedetomidine, and ketaminexylazine for general anesthesia during oral procedures in rice rats (Oryzomys palustris). J Am Assoc Lab Anim Sci. 2019;58(1):40-9. https://doi.org/10.30802/AALASJAALAS-18-000032.

27. Teixeira RKC, Calvo FC, Santos DR, Araújo NP, Tramontin DF, Costa LVP, Barros RSM. Criteria for assessing peripheral nerve injury. Behavioral and functional assessment in non-operated Wistar rats. Acta Cir Bras. 2020;35(7):e202000702. https://doi.org/10.1590/s0102865020200070000002 